\title{
DEMAND AND CAPACITY BALANCING THROUGH PROBABILISTIC QUEUING THEORY AND GROUND HOLDING PROGRAM FOR EUROPEAN AIR TRANSPORTATION NETWORK
}

\author{
Barış BAŞPINAR ${ }^{1, ~ *}$, Emre KOYUNCU ${ }^{2}$ \\ ${ }^{1}$ Controls and Avionics Research Group, Aerospace Research Center, İstanbul Technical University, \\ 34469, İstanbul, Turkey \\ ${ }^{2}$ Department of Aeronautics Engineering, Faculty of Aeronautics and Astronautics, İstanbul Technical University, \\ 34469, İstanbul, Turkey
}

\begin{abstract}
In this paper, we investigate the effect of local disturbances in European airports over the global delay characteristics of the air traffic network with and without ground holding program. First, the historical air traffic data is used for analyzing the busiest European airports. Then, network models are constructed in order to simulate balancing the demand and capacity and delay propagation across the network under disruptive events. These models, which are stochastic Queuing Network Models, are used to run in different scenarios where the capacities of airports are reduced to simulate local disturbances (e.g. heavy rain in the airport areas, air traffic controller strikes, etc.). The impact of a local capacity reduction in the airports to the European network are analyzed, and performances of these models, with and without ground holding implementation (i.e. Queuing Network Model (QNM) and Queuing Network Model with Ground Holding (QNM-GH)), are compared. It is shown that demand and capacity are in balance for both models. It is seen that the ground delay policy in QNM-GH causes to shift the delays from arrival to departure. Furthermore, it is declared that QNM-GH outperforms QNM in uncertainty reduction. Moreover, it is seen that the total delay cost of the network with QNM, which is $280845 €$, is greater than the total delay cost of the network with QNM-GH, which is $268500 €$, in same case study.
\end{abstract}

Keywords: Air transportation, Air traffic modelling and simulation, Demand and capacity balancing

\section{INTRODUCTION}

The air transportation industry and its role in modern life are rapidly growing. It is expected that the number of commercial flights will almost double from 26 million to 48.7 million and 13.5 trillion passenger-kilometer will be flown by 2030, which is almost the triple of what is flown by airlines today [1]. The total number of new deliveries for both passenger and freighter aircraft are expected to be close to 32,600 , while 14,000 passenger aircraft will be retired or converted to freighter [1]. However, the airspaces have a fixed amount of capacity, and the number of airports to be built is not large enough to accommodate such increase in the demand. Therefore, the Air Traffic Management (ATM) system must go under an operational transformation in order to increase its efficiency to deal with these challenges. Meeting the capacity demand and minimizing arrival flight delays are among the most critical challenges of Flight Path 2050 [2].

New procedures and concepts that are being developed in Single European Sky ATM Research (SESAR) and Next Generation Air Transportation System (NextGen) are leading to a global paradigm shift from air traffic "control" to efficient air traffic "management", which requires redesigning the ATM system. The first step to designing such a complex system is to perform rigorous analysis through the existing data. Once we have the parametric model on the network, then one can add stochastic behavioral dynamics in order to catch the occasional effects on the system. Airports of the air traffic network are 
most fragile parts of the system as the most influential events to the flow occur in there. Therefore, focusing on the airports on model construction is the most common in such studies.

In this work, we have constructed data analytic approach to model the European ATM Network Flow to quantify the dynamics of delay propagation across the network and balance the demand and capacity. In order to model the European Air Traffic Network, we have utilized historical data of European air traffic flow and queuing models of air sectors. Specifically, we have constructed two different ATM network models allow us to propagate induced delays, which are airport-based queuing network model (QNM) and airport-based queuing network model with ground-holding application (QNM-GH) and compared their behaviors under disruptive events (e.g. heavy rain, crew strike) leading airports to mandatory capacity reduction. A case study is performed to apply demand and capacity balancing in airports. Following subsection provides previous research efforts on modeling air transportation network.

\subsection{Previous Works}

Several researchers focused on different approaches to model the air transportation network. Eulerian network models are generated to model en-route air traffic flow and strongly inspired by hydrodynamic theory, especially by Daganzo's Cell Transmission Model [3, 4] and the work of Lighthill, Whitham and Richards [5, 6]. The Large-Capacity Cell Transmission Model that uses a graph-theoretic representation of air traffic flow is represented in the study of Sun and Bayen [7]. A discrete time dynamical system is used to model the traffic flow on the network. In this model, traffic flow is modelled by a deterministic linear system with unit time delay. Another model is presented by Menon et al. [8]. The modelling technique is to aggregate the air traffic into control volumes, which are line elements. The model accounts ATC actions and handles merging and diverging air traffic flows. Bayen et al. [9] use the partial differential equations derived from conservation of mass in a control volume and it relies on a modified version of the Lighthill-Whitham-Richards (LWR) partial differential equations $[5,6]$. Controller design strategies are also applied to these models to regulate the aircraft count in differential sectors under a legal threshold [10-12].

Machine learning is another approach to model the delay prediction in air transportation. In [13, 14], a network-based delay prediction model is constructed. The model uses Random Forest (RF) algorithm and the aim of this approach is to predict the departure delay state of a certain route in the network instead of predicting individual flight delays. The study in [15] also focuses on departure delay prediction using machine learning techniques borrowing ideas from Genetic Algorithm. Moreover, MITRE Corporation focused on network modelling to mimic local delay propagation and developed two different models to simulate of delay propagation on the nationwide airport and airspace network in the United States. The Detailed Policy Assessment Tool (DPAT) [16], which is the successor of the National Airspace System Performance Analysis Capability (NASPAC) tool, is able to propagate delays across the network when the capacity of an airport is reduced due to external events, but it does not utilize the information regarding aircraft itineraries, which might lead to unreliable predictions.

On the other hand, there are also agent-based simulation models for delay propagation, such as Future ATM Concepts Evaluation Tool (FACET) [17]. LMINET (Logistics Management Institute - Network) and LMINET2 [18] are national queuing network models, which represent airports airports as $\mathrm{M}(\mathrm{t}) / \mathrm{E}_{\mathrm{k}}(\mathrm{t}) / 1$ queues. In queuing theory, a system is represented in a form of $\mathrm{A}|\mathrm{B}| \mathrm{m}$, where $\mathrm{A}$ and $\mathrm{B}$ indicate the probability distribution of user inter-arrival times and of service times, respectively, and $\mathrm{m}$ is the number of identical parallel servers in the queueing system. In $\mathrm{M}(\mathrm{t}) / \mathrm{E}_{\mathrm{k}}(\mathrm{t}) / 1$, the aircraft arrival time is modeled as an Exponential distribution and the airport service time is modeled with Erlang Distribution. The Approximate Network Delays (AND) model is another popular model that is designed by $[19,20]$. The modelling approach in AND and LMINET2 are similar. However, calculating strategies of the local queuing delays are different. The advantages of this approach are that it is computationally 
cheap, and it can model both deterministic and stochastic effects. Another methodology, which is seen in [21, 22], focuses on optimization based or algorithmic approaches. In [22], a slot allocation model is generated by considering the structure of the air traffic network as a mathematical programming problem, so the interdependence of the slots at different airports is also considered. By using this methodology, allocation with grandfather rights are compared with free allocation. In [21], it is also used similar methodology where an integer programming model for large-scale instances of the air traffic flow management problem is presented. Sectors and airports are modelled with their capacities in this model. Further, a network-based air traffic model is developed by Hong and Harker [23]. The values of landing slots at airports are estimated using this model. An algorithm integrated with constraint programming optimization paradigm is presented by [24] to reschedule the flight plan using delays and swaps. In [25], several different meta-heuristic such as hill-climbing, simulated annealing, and genetic algorithm are used to solve the recovery problem.

The paper is organized as follows. The Section 2 explains historical traffic data processing and dimensionality reduction in number of airports in the European Network. The validation of the applied strategy is also given in Section 2. Section 3 presents the data-driven network models and their design principles. Then, Section 4 provides simulation results for percentile capacity reduction and gives comparison of these network models.

\section{TRAFFIC DISTRIBUTION IN EUROPE}

This section provides the analysis of traffic flow and characteristics of European's airports. For these purposes, 2 months of historical traffic data, which contains flights (including transits) in Europe during June 2014 and November 2014, is used. Historical air traffic data has been extracted from the ALLFT+ data set, collected by EUROCONTROL.

The all movements for an airport are extracted through all flights, which are both departure and arrival flights, for the airport and the given month. The average daily movement is calculated by dividing the number of total flights to the number of days for the given month. Then, the busiest airports in 2014 are given in Table 1. It is observed that approximately $20 \%$ of all movements in Europe originated from or arrived at these 8 busiest airports.

Table 1. Busiest Airports in Europe (June - November 2014)

\begin{tabular}{|l|l|l|l|l|l|}
\hline June 2014 & \multicolumn{3}{l|}{ November 2014 } \\
\hline$\#$ & Airport & Mov./Day & $\#$ & Airport & Mov./Day \\
\hline 1 & EDDF & 1394 & 1 & EGLL & 1252 \\
\hline 2 & LFPG & 1385 & 2 & EDDF & 1228 \\
\hline 3 & EGLL & 1340 & 3 & LFPG & 1204 \\
\hline 4 & EHAM & 1325 & 4 & LTBA & 1148 \\
\hline 5 & LTBA & 1232 & 5 & EHAM & 1141 \\
\hline 6 & EDDM & 1096 & 6 & EDDM & 1021 \\
\hline 7 & LEMD & 1000 & 7 & LEMD & 920 \\
\hline 8 & LIRF & 962 & 8 & LIRF & 779 \\
\hline $19 \%$ of all movements in Europe & $22 \%$ of all movements in Europe \\
\hline
\end{tabular}

It is obvious that an airport generates delays when it reaches its capacity limit. In Europe, most of the airports have daily movements under a 100, meaning that their hourly movements are less than 4 . If an airport has only 1 runway, then the hourly capacity of this airport will be around 30 . It is assumed that, these kinds of airports operate with far less demand than their limits, and do not injects additional delay into the network. Considering this operational reality, we have chosen to aggregate these airports as a single entity for the sake of low dimensionality. 
In addition to the airports in Europe, non-European airports also inject traffics into European airports. Figure 1 depicts the traffic flow over Europe in directed graphs that are generated by using the actual flight dataset. Vertices represent specific regions and weights on the edges represent the percentage of air traffic flow from one region to another. The letters in the graphs represent the regions, which are provided by ICAO, i.e. L: Southern Europe, Israel and Turkey; E: Northern Europe; U: Russia; K: United States; O: Pakistan, Afghanistan and most of Western Asia; G: Western parts of West Africa and Maghreb.

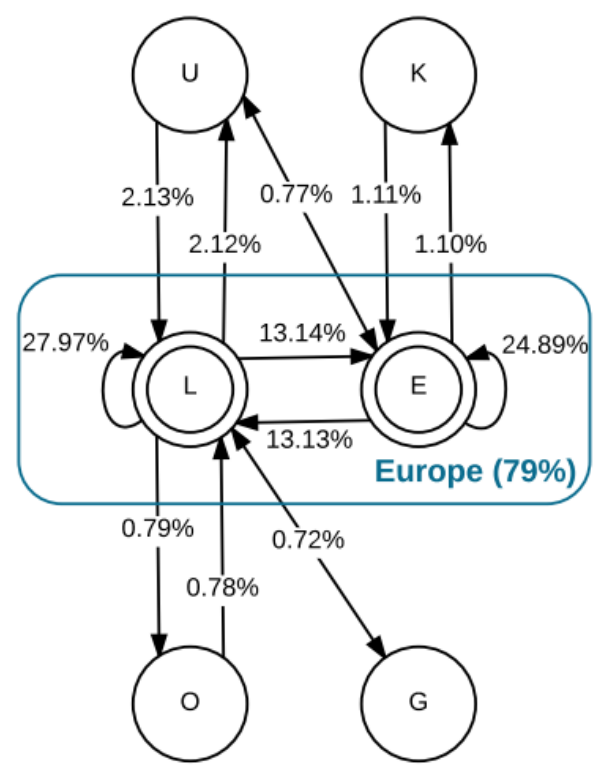

(a)

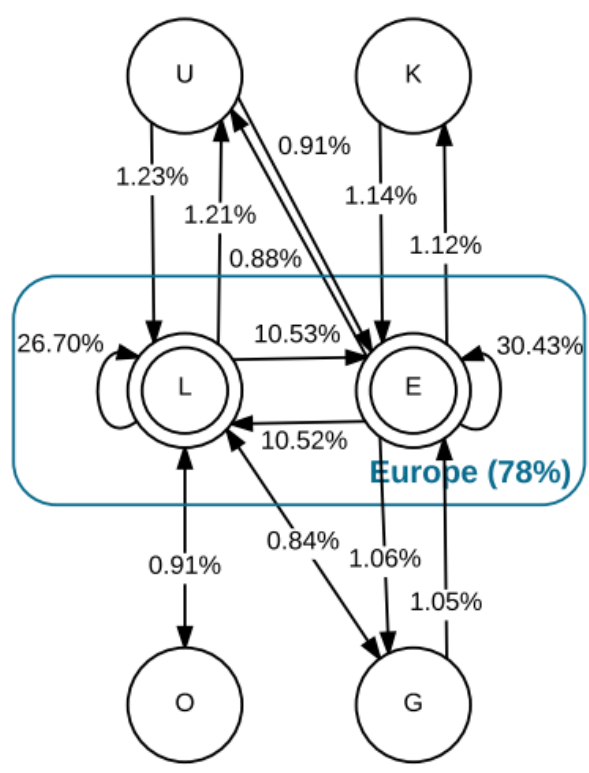

(b)

Figure 1. Regional Air Traffic Flow in Europe (a) in June 2014 and (b) in November 2014

In this study, the analysis and model development focuses on the European region. Moreover, due to the data availability, all of the non-European airports are considered as an aggregated airport. Focusing Europe airports represent a strong approximation with at least $78 \%$ actual flow coverage, which is seen in Figure 1.

These assumptions allow us to aggregate all "minor" airports and non-European as a single airport. For the modelling purpose, the total number of airports has been reduced to 103 airports, including 102 European major airports and an aggregated airport for Network Model.

\section{DATA DRIVEN NETWORK MODEL WITH/WITHOUT GROUND HOLDING POLICY}

In this section, we explain data-driven network model, which is a queuing network model with ground delay policy, for European Air Traffic Network. Uncertainties in the network are inherently reflected through stochastic nature of the queuing network model. One can also construct pure deterministic models by following very similar data-driven approach as well.

To design an airport-based queuing network model, this study closely follows $[19,20]$ such that very similar recursive methodology is used. Specifically, the airport-based queuing network model (QNM) consists of two layers, which are the local queuing delay calculator (LQDC) and the global delay propagation (GDP) algorithm. These layers follow each other in a recursive fashion. 
LQDC generates local delays according to First Come First Served (FCFS) procedure. During the delay generation process, each airport is modelled as a single server that serves both arrival and departure flights. In queuing theory, a system is represented in a form of $\mathrm{A}|\mathrm{B}| \mathrm{m}$, where $\mathrm{A}$ and $\mathrm{B}$ indicate the probability distribution of user inter-arrival times and of service times, respectively, and $m$ is the number of identical parallel servers in the queueing system. $\mathrm{M}, \mathrm{D}, \mathrm{E}_{\mathrm{k}}$ and $\mathrm{G}$ letters are commonly used letters used to represent different types of probability distributions, where M symbolizes the Poisson (i.e., negative exponential pdf for user inter-arrival times or for service times) and stands for "memoryless", D symbolizes deterministic (i.e., inter-arrival or service times are constant), $\mathrm{E}_{\mathrm{k}}$ symbolizes kth-order Erlang distribution and $\mathrm{G}$ symbolizes general distribution (i.e., any type of the model). In model, airports can be modelled as $\mathrm{D}(\mathrm{t}) / \mathrm{D}(\mathrm{t}) / 1$, which represents the deterministic arrival and service times, or $\mathrm{M}(\mathrm{t}) / \mathrm{E}_{\mathrm{k}}(\mathrm{t}) / 1$, which represents the exponential aircraft arrival times and Erlang airport service times. Parameters of these distributions are inferred from the flight data and capacity declarations of airports. LQDC calculates local delays for each airport separately, and the global effects of local delays are calculated through the propagation algorithm (Figure 2).

LQDC considers demand profiles for each airport. These profiles have a discrete structure: one day is split into 15-minutes time windows. $\mu_{a}(h)$ represents demand in an airport $a$ at time window $h$. It is the total number of flight for both take-off and landing. The other input is $\lambda_{a}(h)$, which represents the service rate. Through these inputs, LQDC generates $W_{a}(t)$ local delay function dependent on time in airport $a$.

In GDP level, the algorithm uses $W_{a}(t)$ sequences, connected flights, scheduled and adjusted departurearrival times for each flight. $f$ represents the current flight while $f^{\prime}$ represents the previous flight of the same aircraft (i.e. same tail number). At the beginning of the propagation algorithm, delay situations are determined. The delay is accepted as "significant" if the departure or arrival time of $f$ needs to be adjusted, meaning that a shift to other slots is essential because of its previous move $f^{\prime}$. Departure and arrival times of all flights are regulated through propagation algorithm and evaluated with the following equations:

$$
\begin{aligned}
& A D(f)=\max \left[S D(f), S D(f)+\left(A A\left(f^{\prime}\right)-S A\left(f^{\prime}\right)\right)+W_{d\left(f^{\prime}\right)}\left(A A\left(f^{\prime}\right)\right)-\operatorname{slack}\left(f^{\prime}, f\right)\right] \\
& A A(f)=\max \left[S A(f), A D(f)+W_{o(f)}(A D(f))+(\text { flight time } o(f) \text { to } d(f))\right]
\end{aligned}
$$

In these equations, $A D(f)$ is the regulated departure time of flight $f$. $A A$ is the regulated arrival time, $S D$ is the scheduled departure time and $S A$ is the scheduled arrival time. $o(f)$ is the origin airport of the flight $f$ and $d(f)$ is the destination airport. Let $\operatorname{turn}\left(f^{\prime}, f\right)$ be the turnaround time, which is evaluated as $\operatorname{turn}\left(f^{\prime}, f\right)=S D(f)-S A\left(f^{\prime}\right)$. Let minturn $\left(f^{\prime}, f\right)$ be minimum time to handle the ground services of flight $f$. The $\operatorname{slack}\left(f^{\prime}, f\right)$ can be given as $\operatorname{slack}\left(f^{\prime}, f\right)=\operatorname{turn}\left(f^{\prime}, f\right)-\operatorname{minturn}\left(f^{\prime}, f\right)$. Once we have the regulated departure and arrival times, demand profiles are updated for each airport. This recursive process between LQDC and propagation algorithm repeats until any significant delay does not stay in the network. This process is given in Figure 2. 


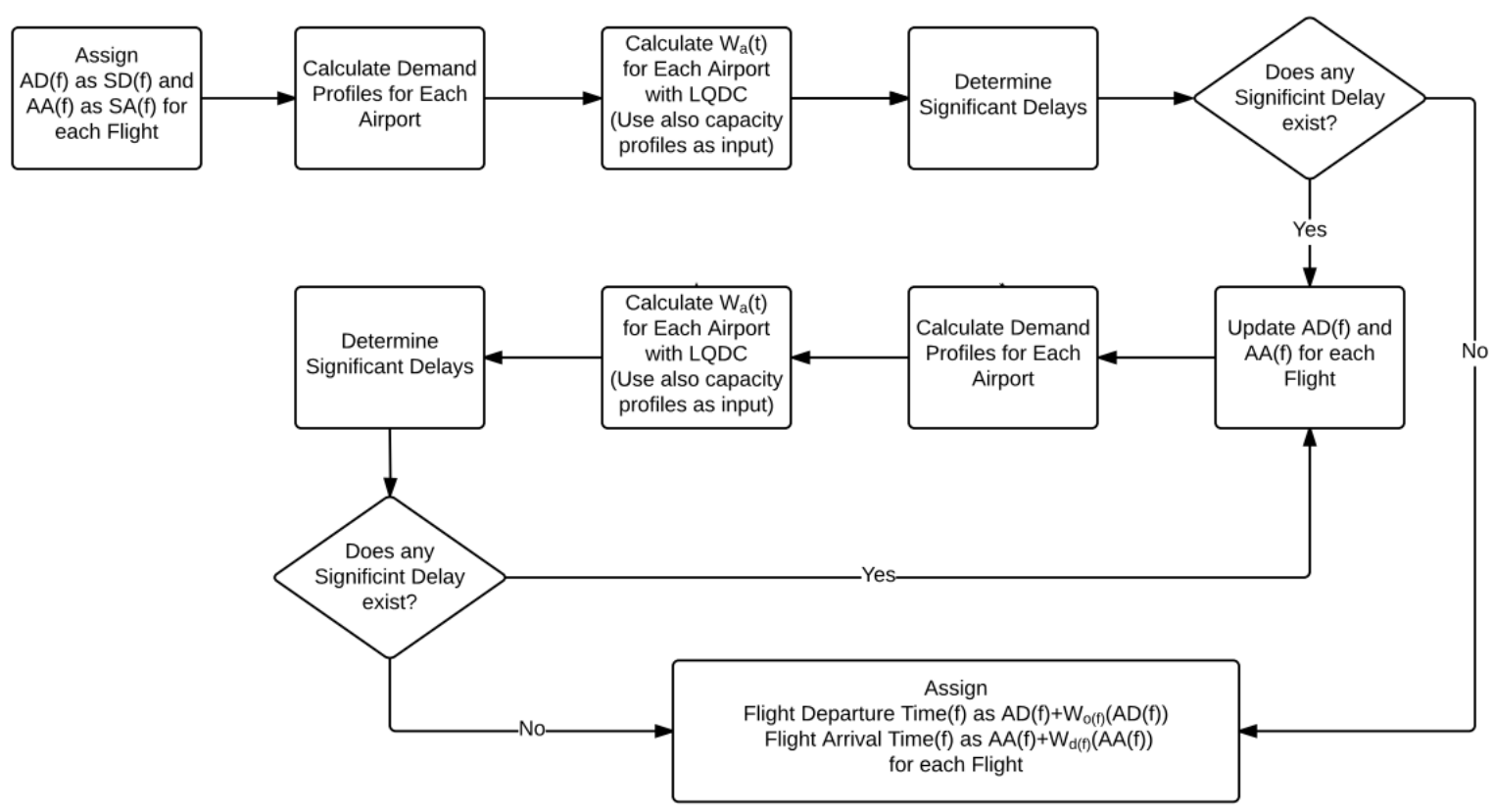

Figure 2. Flow Chart for Algorithm of Queuing Network Model

In QNM, delays are equally distributed to departure and arrival traffic through FCFS procedure in LQDC stage. This approach simply holds that if a departing aircraft takes $x$ minutes of delay, the following arrival aircraft, which is served in the same runway, will take approximately the same amount of delay. Considering fuel consumption and operational costs, the ground delay is preferred to airborne delay. Therefore, a ground-holding mechanism is integrated into QNM. The flow chart of Airport Based Queuing Network Model with Ground-Holding Program is given in Figure 3. In this algorithm, problematic airports are identified at the beginning of the loop. A problematic airport is defined as the airport that has local delays greater than 15 minutes. The demand $\lambda_{a}(t w)$ and capacity $\mu_{a}(t w)$ rates in each time window $t w$ in these airports are evaluated. The flights in similar time windows holding the condition of $\lambda_{a}(t w) / \mu_{a}(t w)>1$ are delayed (i.e. ground delay) until the condition $\lambda_{a}(t w) / \mu_{a}(t w) \leq$ 1 is satisfied. Another constraint is that the given delay in this procedure is smaller than 15 minutes. An aircraft can be moved to the following time window. More than one shift is not allowed in a single iteration. After ground delays are given, demand profiles and local delays are redistributed. 


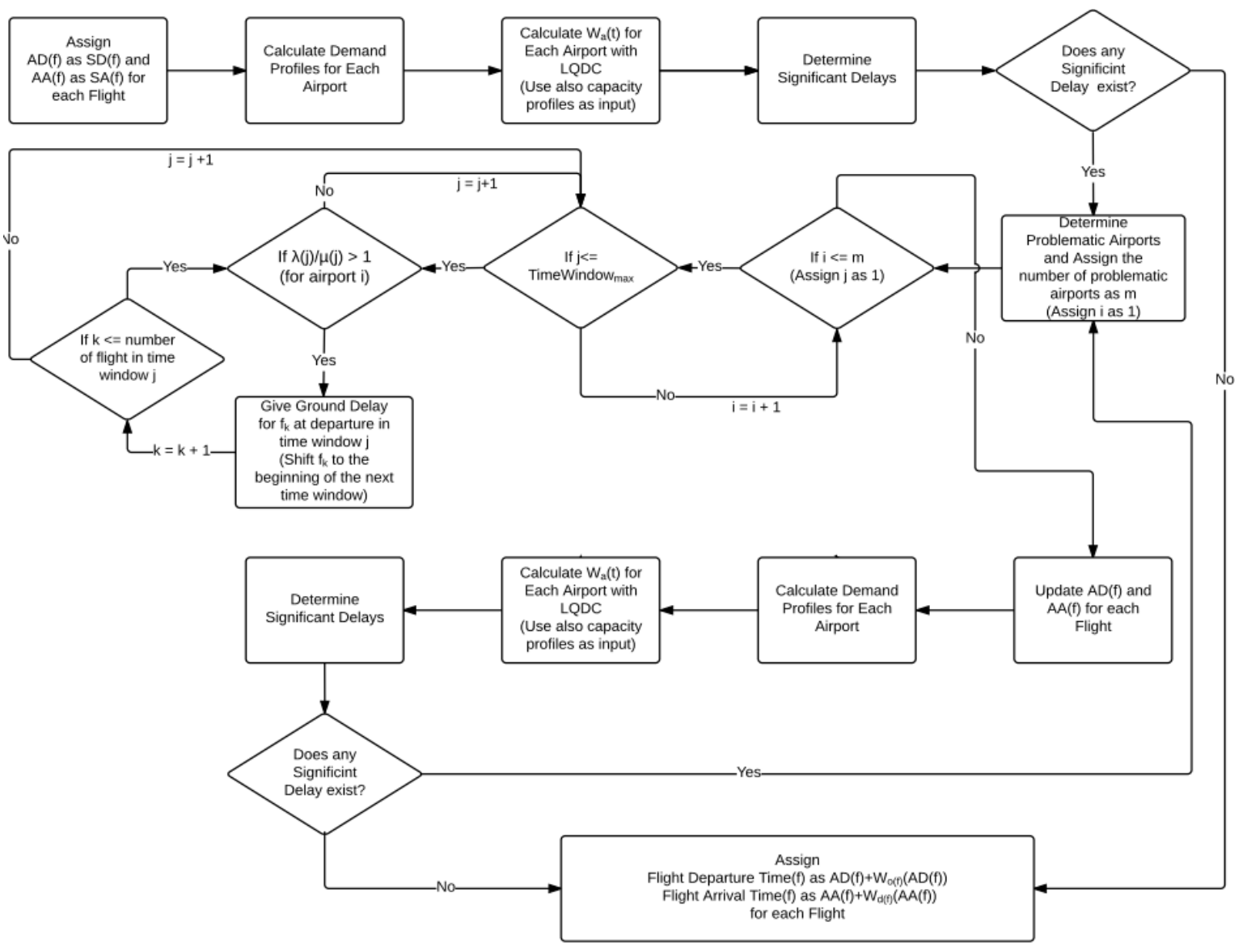

Figure 3. Flow Chart for Algorithm of Queuing Network Model with Ground-Holding

\section{IMPLEMENTATION, RESULTS AND DISCUSSION}

For the implementation purpose, real flight traffic data for a randomly selected day, March 2, 2016, is used. Firstly, operations under nominal conditions are investigated. Demand and capacity balancing through QNM under nominal conditions in EDDF and LFPG are shown in Figure 4 and Figure 5. Secondly, similar capacity reduction scenario is applied to different airports. In this scenario, $45 \%$ capacity reduction in LFPG (Paris Charles de Gaulle) from 08:00 to 10:00 and 50\% capacity reduction in EDDF (Frankfurt) from 10:00 to 12:00 is performed. The results and the performances of the network models are analyzed and compared from the perspective of demand and capacity balancing (DCB). Stochastic versions of both QNM and QNM-GH are evaluated separately. 100 different simulations are performed for each stochastic model to show the impacts of stochasticity. Simulation results for different network models are given in Figure 6-11. Finally, costs of models are compared considering ground holding and airborne delays through deterministic queuing delay calculator $(\mathrm{D}(\mathrm{t}) / \mathrm{D}(\mathrm{t}) / 1)$ for $\mathrm{QNM}$ and QNM-GH. In this situation, 45\% and 50\% capacity reduction for LFPG and EDDF is also applied.

In Figure 4 and Figure 5 related to the nominal operation, deviations from average demands are presented with light blue bars, while average demands are presented with dark blue bars. It is shown that demands in EDDF and LFPG are regulated where demand trends mostly stay under declared capacity curve. However, some capacity excesses are seen due to stochasticity in inter-arrival and service times (as seen with light blue bars in Figure 4 and Figure 5). 


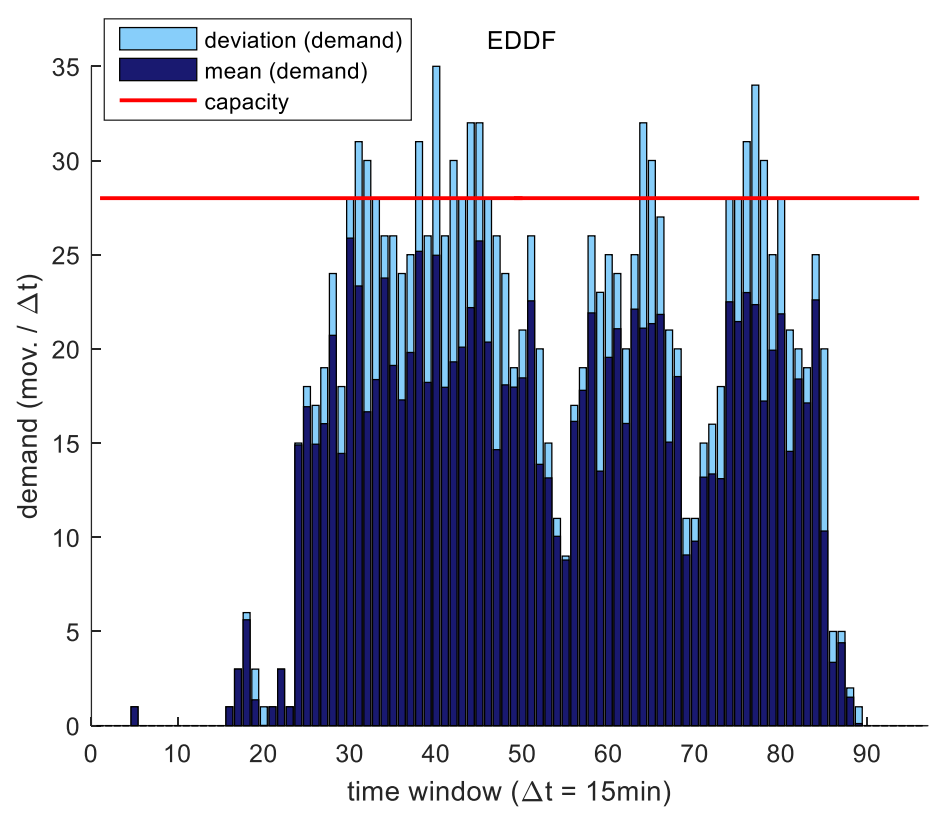

Figure 4. Demand and Capacity Profiles in EDDF as a result of QNM for nominal conditions

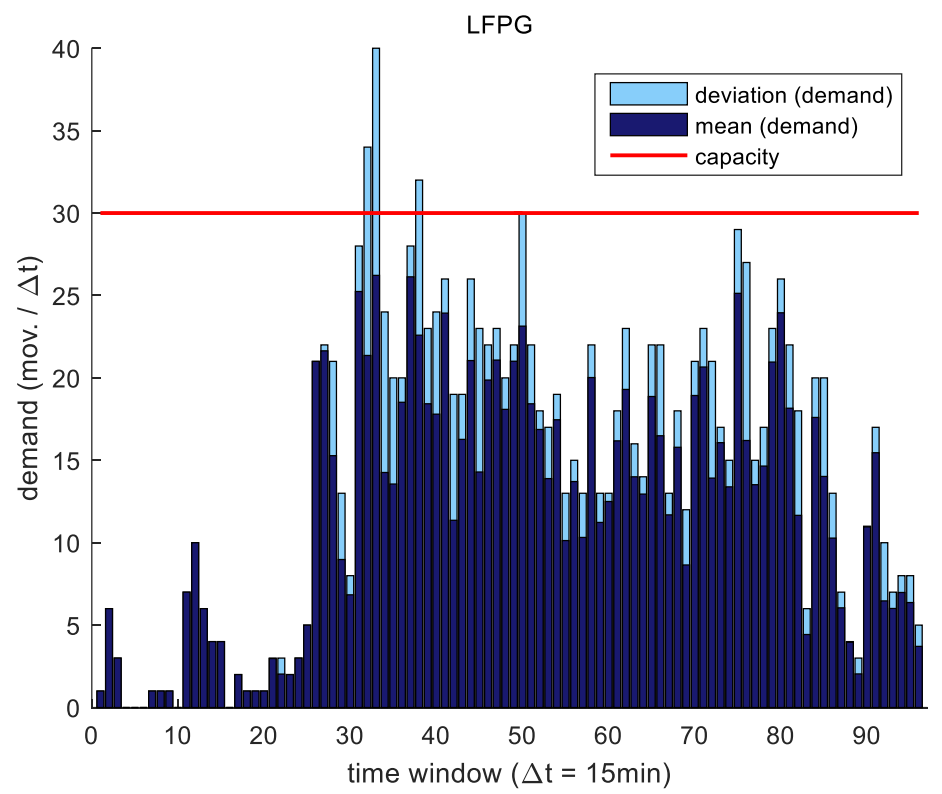

Figure 5. Demand and Capacity Profiles in LFPG as a result of QNM for nominal conditions

Figure 6 and Figure 7 shows the delay profiles in EDDF as a result of capacity reduction scenario, which are evaluated through QNM and QNM-GH, respectively. As seen in the figures, departure delay trend in QNM-GH is greater than in QNM, while QNM-GH has smaller arrival delay trend. This means that ground delay policy in QNM-GH causes to shifting the delays from arrival to departure. Moreover, uncertainty bounds in the delay profile due to stochasticity in turnaround times are also given in Figure 6 and Figure 7. 

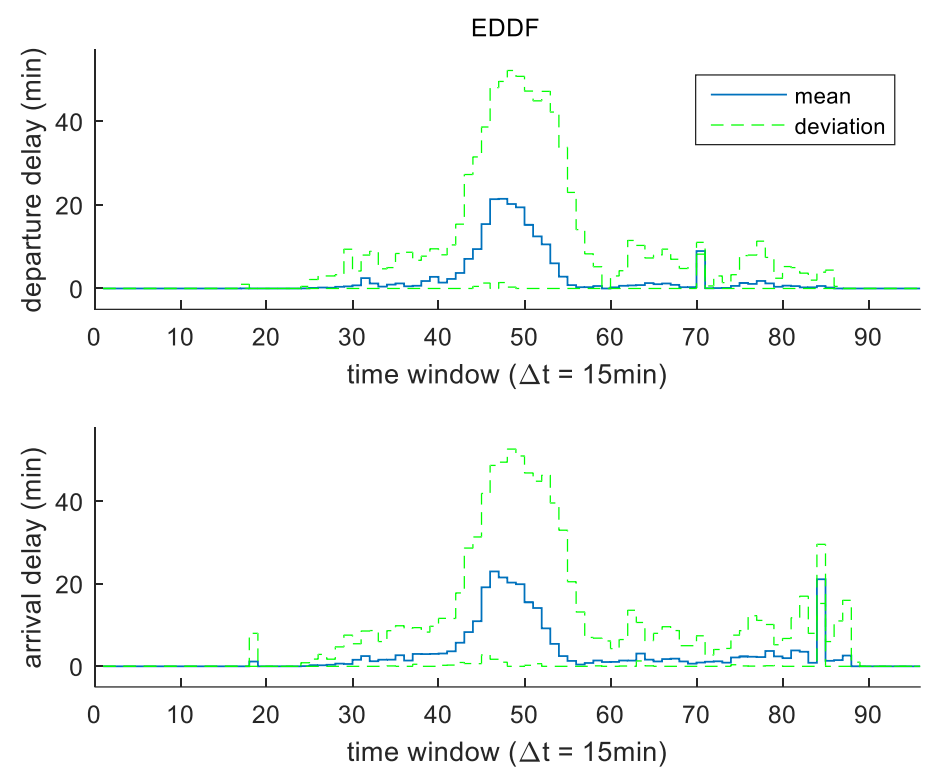

Figure 6. Delay Profiles in EDDF generated by QNM
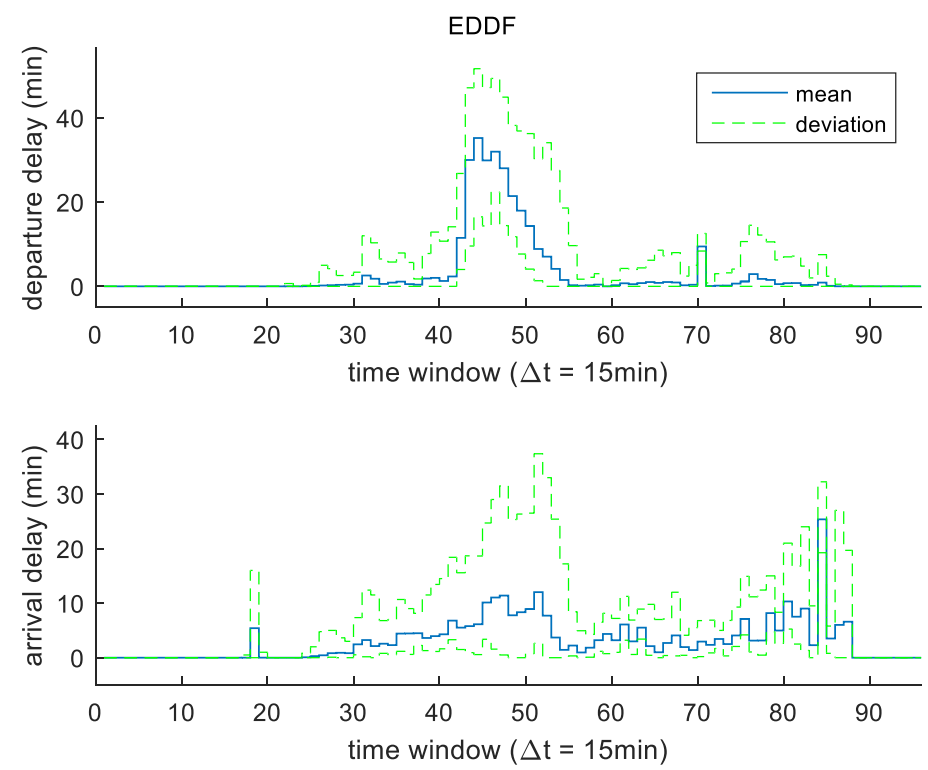

Figure 7. Delay Profiles in EDDF generated by QNM-GH

Under capacity reduction, demand and capacity profiles for the results of QNM and QNM-GH are shown in Figure 8-11 for EDDF and LFPG. These figures are generated through 100 simulation run for each model, and deviations from average demand trend are also shown with light blue bars while average demand trend is shown with dark blue bars. Considering average demand profile, it can be said that demand and capacity are in balance, however, capacity excesses are seen due to stochastic nature of the models. Moreover, it can be seen that QNM-GH outperforms QNM in uncertainty reduction. 


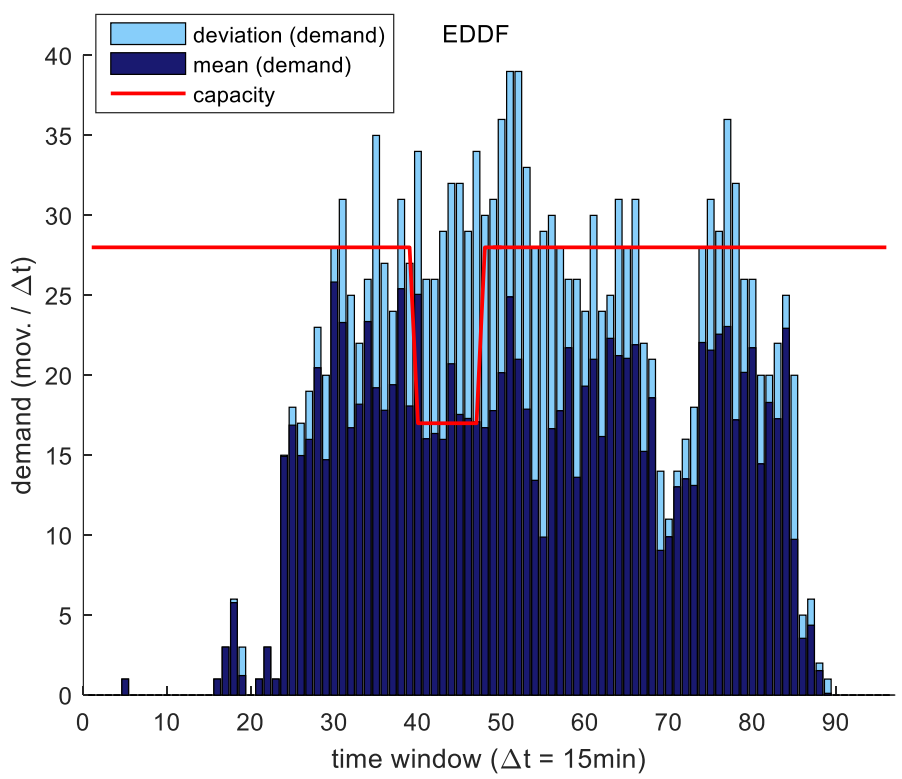

Figure 8. Demand and Capacity Profiles in EDDF as a result of QNM for capacity reduction scenario

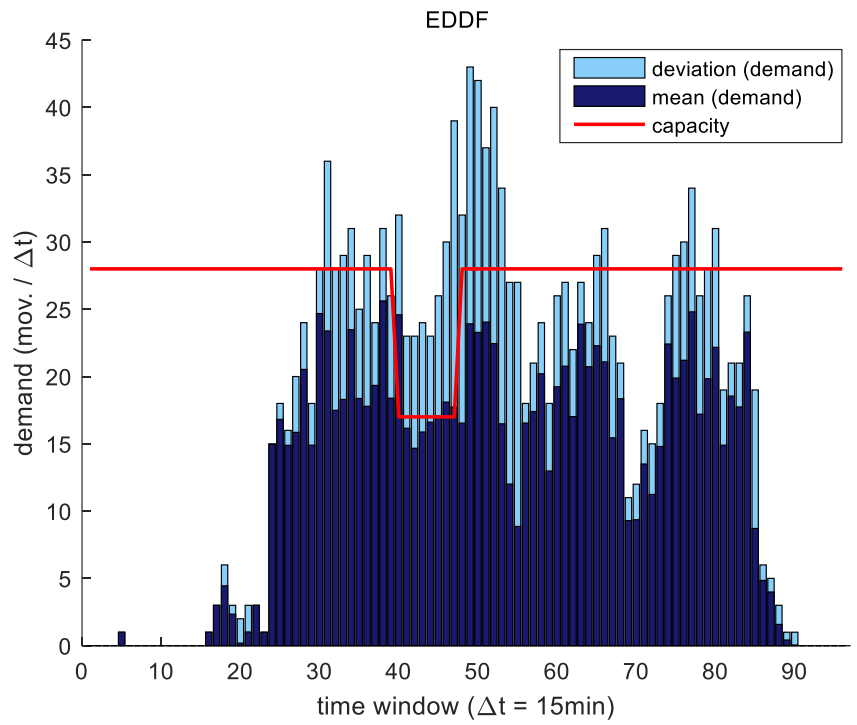

Figure 9. Demand and Capacity Profiles in EDDF as a result of QNM-GH for capacity reduction scenario 


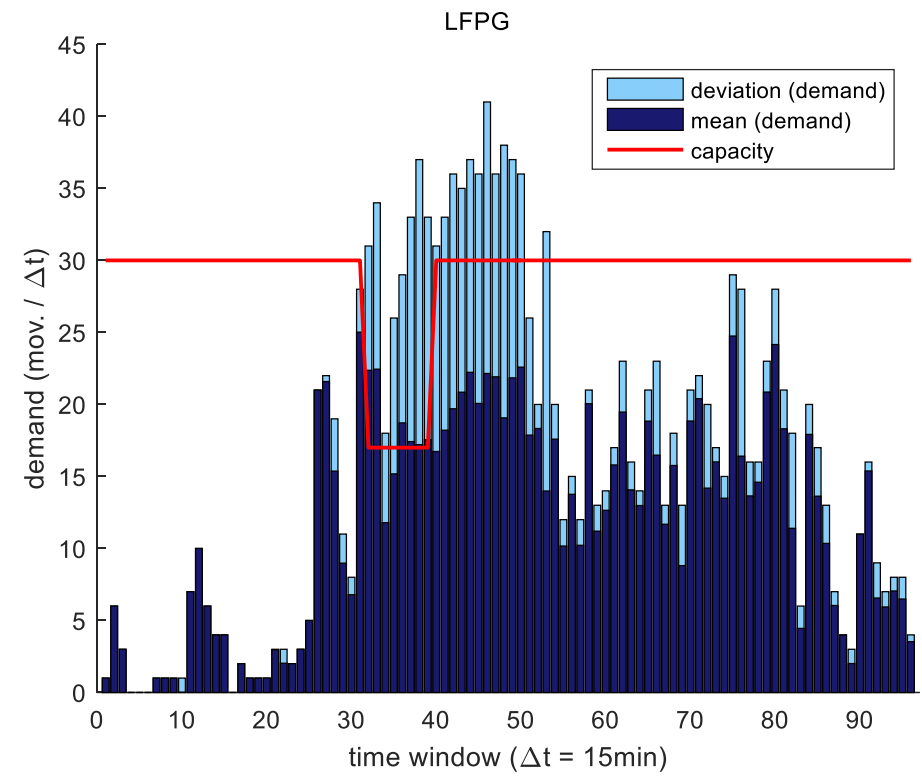

Figure 10. Demand and Capacity Profiles in LFPG as a result of QNM for capacity reduction scenario

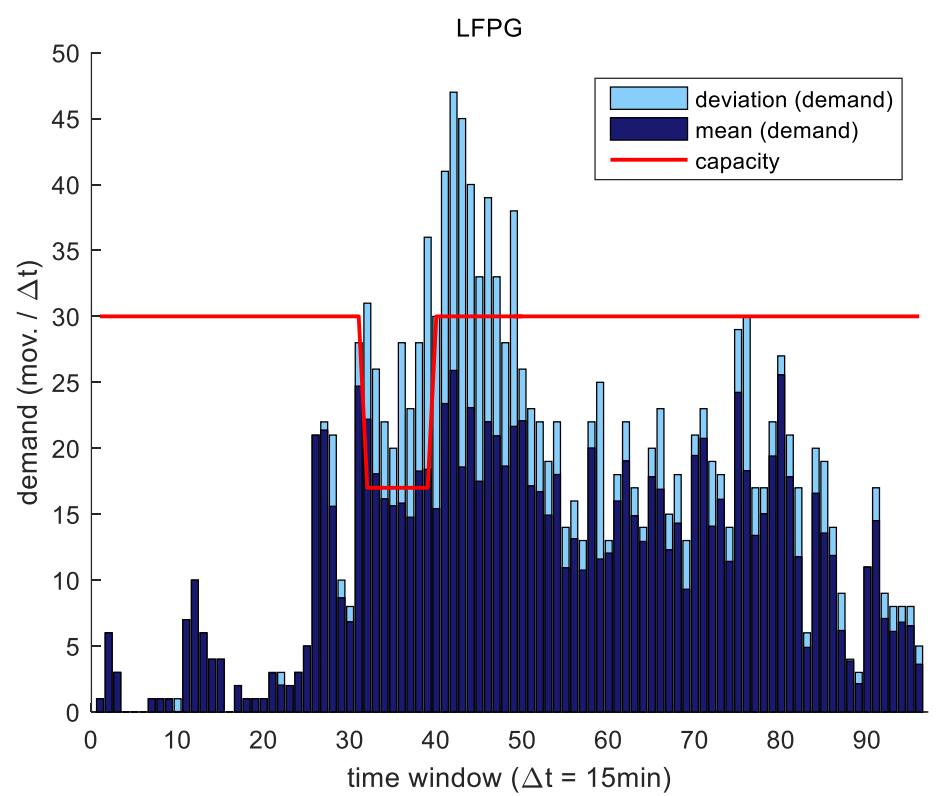

Figure 11. Demand and Capacity Profiles in LFPG as a result of QNM-GH for capacity reduction scenario

Finally, using QNM and QNM-GH algorithms with deterministic queuing delay calculator $(\mathrm{D}(\mathrm{t}) / \mathrm{D}(\mathrm{t}) / 1)$, the scenarios with capacity reduction in LFPG and EDDF are performed. Generated delays for the flights in the network are used to compare the costs of models by considering ground and airborne delays. For this purpose, the cost definition, which is presented in the document of EUROCONTROL [26] is used (Figure 12). In this document, "short" and "long" delays are identified as 15 and 65 minutes, respectively. However, delays at different levels might, of course, seen in real situations. Therefore, in our calculations, delays with 10 minutes to 30 minutes are defined as "short" delay and delays are greater than 30 minutes are described as "long" delays. Moreover, the information about the number of seats 
for each aircraft are not available in the database used in the calculations. In our simulation day, the 88\% of aircraft were in "medium" category that is seen in ICAO's wake turbulence categorization. We have chosen to use an average cost for each delay type without considering the number of seats, and these are presented in Table 2 .

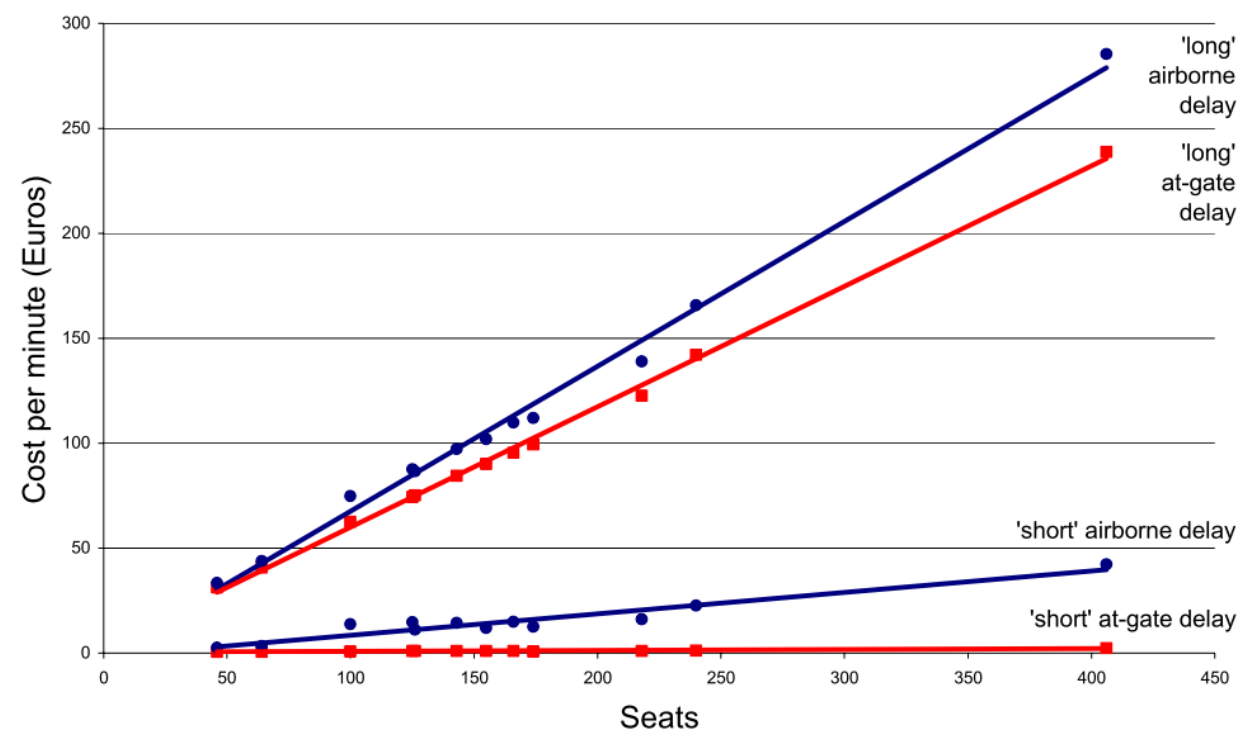

Figure 12. The cost per minute of airborne and at-gate delays according to aircraft seats [26]

Table 2. Mean Cost per minute for Different Delay Status

\begin{tabular}{|l|c|l|l|}
\hline \multicolumn{2}{|l|}{ Short Delay (10 $\mathrm{min}-30 \mathrm{~min})$} & Long Delay $(>30 \mathrm{~min})$ \\
\hline at-gate delay & airborne delay & at-gate delay & airborne delay \\
\hline $0 €$ & $15 €$ & $75 €$ & $95 €$ \\
\hline
\end{tabular}

The amount of total delays obtained from simulations are presented in Table 3. These are the results of two different simulations scenarios, which are generated through QNM and QNM-GH models with deterministic queuing delay calculator.

Table 3. Generated Total Delays from QNM and QNM-GH

\begin{tabular}{|c|c|c|c|c|c|c|c|}
\hline \multicolumn{4}{|c|}{ QNM } & \multicolumn{4}{c|}{ QNM-GH } \\
\hline \multicolumn{2}{|c|}{ Short Delay } & \multicolumn{2}{c|}{ Long Delay } & \multicolumn{2}{c|}{ Short Delay } & \multicolumn{2}{c|}{ Long Delay } \\
\hline $\begin{array}{c}\text { Total } \\
\text { Ground } \\
\text { Delay } \\
\text { (minute) }\end{array}$ & $\begin{array}{c}\text { Total } \\
\text { Airborne } \\
\text { Delay } \\
\text { (minute) }\end{array}$ & $\begin{array}{c}\text { Total } \\
\text { Ground } \\
\text { Delay } \\
\text { (minute) }\end{array}$ & $\begin{array}{c}\text { Total } \\
\text { Airborne } \\
\text { Delay } \\
\text { (minute) }\end{array}$ & $\begin{array}{c}\text { Total } \\
\text { Ground } \\
\text { Delay } \\
\text { (minute) }\end{array}$ & $\begin{array}{c}\text { Total } \\
\text { Airborne } \\
\text { Delay } \\
\text { (minute) }\end{array}$ & $\begin{array}{c}\text { Total } \\
\text { Ground } \\
\text { Delay } \\
\text { (minute) }\end{array}$ & $\begin{array}{c}\text { Total } \\
\text { Airborne } \\
\text { Delay } \\
\text { (minute) }\end{array}$ \\
\hline 4088 & 828 & 3579 & 0 & 4379 & 0 & 3580 & 0 \\
\hline
\end{tabular}


Using the cost per minute values and the total amount of delays, the total cost of delay in the network for each model is calculated to compare them numerically:

$$
\begin{aligned}
& C_{Q N M}=4088 * 0+828 * 15+3579 * 75+0 * 95=280845 €(3) \\
& C_{Q N M_{-} G H}=4379 * 0+0 * 15+3580 * 75+0 * 95=268500 €(4)
\end{aligned}
$$

It can be seen that the total delay cost of the network with QNM is greater than the total delay cost of the network with QNM-GH implementation. It was expected that as the airborne delays in QNM-GH implementation are shifted to the ground-waiting, which has relatively lower operational cost.

\section{CONCLUSION}

This paper presented two different network models to simulate the delay propagation and balance the demand and capacity in case of capacity reduction at certain airports in the European air transportation network. Through the historical air traffic data, actual movements in the Europe were processed, and traffic flow was obtained. Major airports were defined, and other airports were aggregated as to construct reduced dimensional model of large-scale European air traffic network. The total number of airports in European Air Traffic Network was reduced into 103 airports, which includes 102 major European airports and a single aggregated airport. Through dimensionality reduction, two data-driven network models, which are airport-based queuing network model (QNM) and airport-based queuing network model with the ground-holding program (QNM-GH), were constructed. Design principles and algorithms of these approximate models were explained throughout of this paper. Then, the performances of these models that parametrically approximates European air traffic network were compared in balancing demand/capacity through certain simulation scenarios with capacity reductions and uncertainties in airport operations such as turnaround time. The comparison results were given, also provides validation for the models. The future work will be to add air sector and trans-sector queues into the network in order to capture demand and capacity balancing in en-route sectors, which will enable to centrally control traffic flows.

\section{ACKNOWLEDGMENTS}

The author(s) disclosed receipt of the following financial support for the research, authorship, and/or publication of this article: Barış Başpınar was supported by The Scientific and Technological Research Council of Turkey (TUBITAK) with Graduate Research Fellowship.

\section{REFERENCES}

[1] Global market forecast flying by numbers 2015 - 2034. Technical Report D14029463, Airbus, 2015.

[2] Flightpath 2050 Europe's vision for aviation maintaining global leadership \& serving society's needs. Technical report, High Level Group (HLG) on Aviation and Aeronautics Research, 2011.

[3] Daganzo CF. The cell transmission model: A dynamic representation of highway traffic consistent with the hydrodynamic theory. Transportation Research Part B: Methodological 1994; 28(4): 269-287.

[4] Daganzo CF. The cell transmission model, part ii: network traffic. Transportation Research Part B: Methodological 1995; 29(2): 79-93.

[5] Lighthill MJ and Whitham GB. On kinematic waves. ii. a theory of traffic flow on long crowded roads. In Proceedings of the Royal Society of London A: Mathematical, Physical and Engineering Sciences 1955; volume 229, 317-345. 
[6] Richards PI. Shock waves on the highway. Operations research 1956; 4(1): 42-51.

[7] Sun D and Bayen AM. Multicommodity eulerian-lagrangian large-capacity cell transmission model for en route traffic. Journal of guidance, control, and dynamics 2008; 31(3): 616-628.

[8] Menon PK, Sweriduk GD and Bilimoria KD. New approach for modelling, analysis, and control of air traffic flow. Journal of guidance, control, and dynamics 2004; 27(5): 737-744.

[9] Bayen AM, Raffard RL and Tomlin CJ. Adjoint-based control of a new eulerian network model of air traffic flow. IEEE transactions on Control systems technology 2006; 14(5): 804-818.

[10] Work DB and Bayen AM. Convex formulations of air traffic flow optimization problems. Proceedings of the IEEE 2008; 96(12): 2096-2112.

[11] Menon PK, Sweriduk GD, Lam T, Diaz G and Bilimoria KD. Computer-aided eulerian air traffic flow modelling and predictive control. Journal of Guidance, Control, and Dynamics 2006; 29(1): $12-$ 19.

[12] Sun D, Strub IS and Bayen AM. Comparison of the performance of four eulerian network flow models for strategic air traffic management. Networks and Heterogeneous Media 2007; 2(4): 569.

[13] Rebollo JJ and Balakrishnan H. A network-based model for predicting air traffic delays. In: 5th International Conference on Research in Air Transportation; 22-25 May 2012; Berkeley, California, USA.

[14] Rebollo JJ and Balakrishnan H. Characterization and prediction of air traffic delays. Transportation Research Part C: Emerging Technologies 2014; 44: 231-241.

[15] Tu Y, Ball MO and Jank WS. Estimating flight departure delay distributions a statistical approach with long-term trend and short-term pattern. Journal of the American Statistical Association 2008; 103(481): 112-125.

[16] Wieland F. Limits to growth: results from the detailed policy assessment tool [air traffic congestion]. In Digital Avionics Systems Conference; 1997; 16th DASC., AIAA / IEEE, volume 2, 92. IEEE.

[17] Bilimoria KD, Sridhar B, Chatterji G, Sheth K and Grabbe S. Facet: Future atm concepts evaluation tool. Air Traffic Control Quarterly 2001; 9(1).

[18] Long D and Hasan S. Improved prediction of flight delays using the lminet2 system-wide simulation model. In 9th AIAA Aviation Technology, Integration, and Operations Conference (ATIO) 2009; Hilton Head, SC.

[19] Pyrgiotis N. A stochastic and dynamic model of delay propagation within an airport network for policy analysis. Ph.D., Massachusetts Institute of Technology, Massachusetts, USA, 2012

[20] Pyrgiotis N, Malone KM and Odoni. A. Modelling delay propagation within an airport network. Transportation Research Part C: Emerging Technologies 2013; 27: 60-75.

[21] Bertsimas D, Lulli G and Odoni A. An integer optimization approach to large-scale air traffic flow management. Operations Research 2011; 59(1): 211-227. 
Başpınar and Koyuncu / Anadolu Univ. J. of Sci. and Technology A-Appl. Sci. and Eng. 18 (2) - 2017

[22] Castelli L, Pellegrini P and Pesenti R. Airport slot allocation in europe: economic efficiency and fairness. International journal of revenue management 2011; 6(1-2): 28-44.

[23] Hong S and Harker PT. Air traffic network equilibrium: toward frequency, price and slot priority analysis. Transportation Research Part B: Methodological 1992; 26(4): 307-323.

[24] Arias P, Guimarans D and M'ujica M. A new methodology to solve the stochastic aircraft recovery problem using optimization and simulation. In: International Conference on Interdisciplinary Science for Innovative Air Traffic Management (ISIATM); 8-10 July 2013; Toulouse, France.

[25] Aguiar B, Torres $\mathbf{J}$ and Castro AJ. Operational problems recovery in airlines-a specialized methodologies approach. In Progress in Artificial Intelligence 2011; 83-97. Springer.

[26] Cook AJ., Tanner G and Anderson S. Evaluating the true cost to airlines of one minute of airborne or ground delay: final report, 2004. 